\title{
Madness Reconsidered in Susanna Kaysen's Girl Interrupted
}

\author{
Maria Vincent \\ Assistant Professor, Department of English \\ Al Azhar College of Arts and Science, Thodupuzha, Kerala, India \\ https://orcid.org/0000-0002-6407-4258
}

\section{OPEN ACCESS}

Manuscript ID:

ENG-2021-09023564

Volume: 9

Issue: 2

Month: March

Year: 2021

P-ISSN: 2320-2645

E-ISSN: 2582-3531

Received: 06.12.2020

Accepted: 09.01.2021

Published: 03.03.2021

Citation:

Vincent, Maria. "Madness

Reconsidered in Susanna

Kaysen's Girl Interrupted."

Shanlax International

Journal of English, vol. 9, no. 2, 2021, pp. 31-34.

DOI:

https://doi.org/10.34293/

english.v9i2.3564

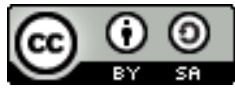

This work is licensed under a Creative Commons Attribution-ShareAlike 4.0 International License

\begin{abstract}
This paper focuses upon the invisible disability of mind and how it is reflected in Susanna Kaysen's Girl Interrupted. Normality and commonality are thus, challenged with the idea of uniqueness. The mental illness is brought forward to let society analyse and understand disability of mind. Mental illnesses are common, yet avoided due to the social prejudice and narrow perspectives. Thus, this paper serves as an awareness of inner struggle reflected in Girl Interrupted, claiming it to be a universal experience and to create a scale of normality.
\end{abstract}

Keywords: Mental Illness, Disability, Susanna Kaysen, Girl Interrupted, Madness and Mind

Who is normal? What criteria is made to state one individual as normal and the other as abnormal or one as abled and the other disabled? What if the normal is the ordinary accustomed majority and abnormal is the creative and extraordinary minority? From ancient times, people with disabilities of body or mind were neglected and rejected from the social and cultural activities, as either the product of evil reality or bestowed bad fate. History visualizes the personalities who protest for the disabilities of mind and body to instil the idea of equality by pronouncing that one who discards the freedom of a disabled man is a cruel representative of social selfishness. Mental illness too stands as a disability. Tobin Siebers, one of the important theorists of disability studies evaluates the concept of disability in his work Disability Theory as:

Disability studies does not treat disease or disability, hoping to cure or avoid them; it studies the social meanings, symbols, and stigmas attached to disability identity and asks how they relate to enforced systems of exclusion and oppression... human being.

Foucault's account on the madness and the subsequent consequences of the madness, as well as the social reliability and understanding of the elements of mind, can be seen reflected in his work Freaks, which was quite controversial upon the social mindset and brought about the real notion of mental instability. Through his work, it is evident that the state of mind and mental health is given significance as well as denials of such health issues are to be considered inhuman and illiterate. So what matters is not just mere discrimination and avoidance faced by disabled ones, but also the unjust demarcation, the concept of inclusion and exclusion, marginalizing disabled ones from prominent realms, creating fickle ideologies of ability and self. The ideal human concept erected by social organizations and manipulative psychological community idols is ruptured to induce the complex idea of uniqueness and individual esteem even amidst disability. 
Girl, Interrupted, is an autobiographical literary piece by Susanna Kaysen where the protagonist is portraying her borderline personality disorder and its subsequent consequences that the author herself went through. She introduces the novel as an autobiographical slice as well as an explanation of her life circumstances and behaviours she underwent in the McLean hospital in Massachusetts. Kaysen herself was proving to the cultural and social domains of the 20th century, that her personality disorder was one of the disabilities of mind rather than the conventional prejudices of senseless and shameless characteristics of an individual made up by the society. She begins the novel with the same concept of insanity that prevails in the world.

Susanna Kaysen's borderline personality disorder is with issues in interpersonal relationships, instability, and inconsistency even about the image of self, trust, and life as such. Thus, these literary relevant works are taken into rumination to prove the disability theory and its scope in the society. Bringing forth the psychological and psychiatric elements on the life of human beings and expelling the reality of conscious sensibility and preconceptions of social constructs, disability theory can be included in the category of literary discipline just like racism, feminism, marginalization, colonization, etc.

Borderline personality disorder, a term coined by Adolph Stern in 1938, is not a mood disorder but a personality disorder which affects the personality of a person and especially his or her interrelationships. For the guidelines to treatment and assess borderline personality disorder, The British Psychology Society and The Royal College of Psychiatrists published Borderline Personality Disorder, where they defined BPD as:

The term 'borderline personality organization' was introduced by Otto Kernberg (1975) to refer to a consistent pattern of functioning and behavior characterized by instability and reflecting a disturbed psychological self-organization... absolute despair, markedly unstable self-image, rapid mood changes, with fears of abandonment and rejection, and a strong tendency towards suicidal thinking and self-harm.

Kaysen was suffering from borderline personality disorder. As her desperate actions to achieve a level of acceptance from her parents too failed, her sense of self was too different from what her parents expected her to be. Unacceptable and weak understanding from the parent's side made her worse. But apart from mood disorders like bipolar, borderline personality disorder can be linked to its genetics, childhood trauma as well as life situations. Depression, suicidal tendencies, and feeling of emptiness is common for many psychiatric disorders, which make it hard for the diagnosis.

Kaysen through her work Girl Interrupted showcases as vibrant women with her true spirit and enthusiasm, but often rejected and misunderstood by people around. Her sense of irritability, disturbed mind, insomnia, and abrupt sexual relationships are too high for her to understand. The novel begins with her suicidal attempt of taking nearly fifty aspirins with alcohol. Later it leads to McLean hospital where she encounters different patients with variant mental disabilities.

Susanna Kaysen too had her life stages to be diagnosed as a patient with mental instabilities. But no one can claim her as incapable, as she is now a published author who many admire. She denotes the different types of sanity we come across the world. "And it is easy to slip into a parallel universe. There are so many of them: worlds of the insane, the criminal the crippled, the sting, perhaps of the dead as well. These worlds exist alongside this world and resemble it, but are not in it". The inability to live up to the expectations of her parents, as most teenagers face, had been a real issue for her. Rather than sticking to the judgmental rules of her parents, she opted for the different ways of her lifestyle, which was quite out of order from the society's norms.

The notable symptoms lead her to such a mental disability that cannot be stated thoroughly as borderline personality disorder does not hold a certain pattern of cause. Historical events, childhood trauma, genetics, etc. can lead to the improper development of personality in a person. Especially when the Id, ego, and superego get confused in their existence, personality disorders occur.

Focusing upon Susanna Kaysen and her mental disability, it is clear on the foreground that she was enduring borderline personality disorder. On June 15,1967 , she was diagnosed by the hospital officials with certain symptoms like "the chaotic unplanned life of the patient at present with progressive de- 
compensation and reversal of sleep cycle. Severe depression and hopelessness and suicidal ideas. History of suicidal attempts. No therapy and no plan at present. Immersion in fantasy, progressive withdrawal, and isolation".

In the chapter, 'my suicide', the unstable thought patterns, suicidal attempts, manipulative behaviours, and seeking relief by self-harm are evident. Through her experience of mental disability, she encountered the vast realms of mental states, whereas, through her work of art, Kaysen is truly letting each one of her readers to see through her and realize how the brain and thought pattern of a mental patient goes Her definition about suicide and the attempt is interesting:

Suicide is a form of murder - premeditated murder. It isn't something you do the first time you think of doing it. It takes getting used to. And you need the means, the opportunity, the motive...The motive is paramount. Without a strong motive, you're sunk.

At the same time, her words profoundly reflect her fascination towards death and rejection of it. Her mind keeps on shifting thoughts. The instability of her mind can be closely studied along with the manipulative nature which is often seen in borderline personality disorder patients

She was unable to withstand the idea of isolation and being locked in a building along with people who exhibit mental disorders. She heard cries, mourning, and screaming. She saw blunt, naked, and uncertain gestures of people, and what made her unique was she had a truly reasonable gesture with standard body language. No one would connect her with mental instabilities. But feel inside she was struggling and thriving to move forward. It is the deep depression and irritation that provokes her to suicide. Along with it the drug abuse and unsafe sexual affairs worsened her condition.

The symptoms Kaysen portrays explicitly stated how she as going through a personality disorder. The dreadful events of scratching her hands to see whether the bones still inside make the readers get into a wide range of illnesses. It is something that most people are unknown.

Sometimes mental disorders are stated through violent actions and screams. Apart from that many patients struggle in dark emptiness without expressive means. Disorders and mental illnesses come in various forms, if you ever thought of dying or killing someone, if you ever felt bad about your skin or got over tensed for simple issues, it is a matter of mind. Mental disabilities can catch up with anybody at any moment. Deviating a thought or pattern of thinking is not always useful. What matters is the proper diagnosis and treatment. Thus, it is necessary to find out the symptoms, educate the human folk about different types of mental illnesses and help them to seek the proper treatment.

Similarly, Kasen withstood such as whirlpools of emotions. Scrutinizing the real source of their illness is relevant here. Borderline personality disorder, apart from the unstable and inconsistent characteristics, possesses a certain Energy of existentialism. Life as a whole seems absurd and empty for someone with a borderline personality disorder.

But they do not assert the exact statement, rather prove the consequences of the statement. Forgetting the achievements of social status and moving in a rhythm of life is not quite easy and adaptable in such cases. What stands supreme is the dilemma of life and death, where one gets thousands of exciting reasons to live in minute and later thousands of depressing elements to quit.

The depression status often considers extreme agony or sadness. But borderline personality disorder is on the border of extreme dilemmas. So, what happens if one does not know his or her identity or an idea of self? The complex perplexed state of one's personality makes them vulnerable to accept the environment around them. The habits, tastes, and concerns frequently shift within their world, which creates chaos. The reality of tiredness that the mind endures is somewhat similar to the body. Thus, understanding mental pain just as physical pain is important in society.

They have to bear the badge of especially weak category even before analysing their talents and skills. It is the concept of the stigma in disability theory. The stigma and over generalization of individuals, behaviours, etc., are seen as an unacceptable procedure. When Kaysen was out of the mental institutions, she had to face the horrific inquiries of society. It isn't always the disease that tortures one, but certainly, the social virus of rumours is to 
be carefully treated. In the novel Girl Interrupted, the mysteries and annoying attitude of society can be clearly. She tried to showcase it in her chapter Stigmatography as:

You spend nearly two years in a loony bin! Why in the world were you in there? I can't believe it! Translation: If you're crazy, then I'm crazy, and I'm not, so the whole thing must have been a mistake. You spend nearly two years in a loony bin? What was wrong with you? Translation: I need to know the particulars of craziness so I can assure myself that I'm not crazy. You spend nearly two years in a loony bin? Hmmm. When was that, exactly? Translation: Are you still contagious?

The thought process and chemicals in the brain have a lot to do with it. Mentally disabled people have some or other problems that are beyond their control. "This brain has problems that are chemical and electrical". Sometimes brain cell's activities and misguided electric impulses can cause troubles in the connectivity and actions of a person. "Too much acetylcholine, not enough serotonin, and you've got depression".

In other cases, the hormone function can bring forward changes in a person's behaviour. So, considering mental illness in a single lens is not usually adequate. There are many reasons to claim one as a mentally disabled patient.

People out there are silently suffering and killing themselves because the world cannot see their pain. Mental illness isn't a wound that bleeds and you cannot see the blood oozing out. But mental illness is a very series condition created by psychological, biological, social, or environmental issues. Even though the society and family have a lot to do with, people with mental illness have to take the blame for themselves and are treated differently. It is just like a rape victim who travels through trauma for her entire life, expanding herself to be an extreme melancholic or an extrovert who loves to be in unsafe and unstable sexual relations. Sometimes mental illness is invisible and thus disabled mind stays unseen.

The real issue arises due to the commonality and normality. The majority which upholds the societal norms are common. One who is deviated from such a common feather is discriminated against and expelled. Their vanishing nature was never traced. But later the theories and movements led to the upbringing of such vanished statements and arguments.

Today, in the modern world we can see many disabled people growing bolder and popular just because of their unique skills and talents. Thus, it is essential to learn that human nature in itself inhabits the concept of disability as well as the unlimited possibilities. The time has exceeded to throw away the prejudices and social stigma against disabled people. Human beings are not limited to a particular manner, race, complexion, character, or anything. Each person is individually totally different. Thus, one must encourage and respect the changes in another. That's where the true humanity begins and discrimination ends.

\section{References}

Adams, Timothy Dow. "Borderline Personality: Autobiography and Documentary in Susanna Kaysen's Girl, Interrupted." Life Writing, vol. 2, no. 2, 2005, pp. 119-137.

Antolin, Pascale. "Challenging Borders: Susanna Kaysen's Girl, Interrupted as a Subversive Disability Memoir." European Journal of American Studies, 2020.

Kaysen, Susanna. Girl, Interrupted. Virago, 2012. Krawitz, Roy, and Wendy Jackson. Borderline Personality Disorder. OUP, 2008.

Krawitz, Roy. "Borderline Personality Disorder: Attitudinal Change Following Training." Australian \& New Zealand Journal of Psychiatry, vol. 38, no. 7, 2004, pp. 554-559.

Manning, Shari Y. Loving Someone with Borderline Personality Disorder. Guilford Press, 2011.

Marshall, Elizabeth. "Borderline Girlhoods: Mental Illness, Adolescence, and Femininity in Girl, Interrupted." The Lion and the Unicorn, vol. 30, 2006, pp. 117-133.

Siebers, Tobin. Disability Theory. University of Michigan Press, 2008.

\section{Author Details}

Maria Vincent, Assistant Professor, Department of English, Al Azhar College of Arts and Science, Thodupuzha, Kerala, India, Email ID: maria18vincent@gmail.com 